\title{
EFFECT OF TRANSFERSOME ON THE STABILITY AND ANTIOXIDANT ACTIVITY OF GLUTATHIONE IN ANTIAGING CREAMS
}

\author{
HARMITA HARMITA*, ISKANDARSYAH, FRIAINI ZAHRA MURTI
}

Department of Pharmacy, Faculty of Pharmacy, Universitas Indonesia, Depok, Indonesia. Email: igakadeharmita@gmail.com

Received: 26 September 2019, Revised and Accepted: 17 December 2019

ABSTRACT

Objective: Glutathione is an important antioxidant compound that is added to various cosmetic preparations. This study compared the stability, antioxidant activity, and penetration of glutathione creams formulated with and without transfersome, a commonly used carrier system.

Methods: The particle size of the transfersome was $55.65 \mathrm{~nm}$, with a polydispersity index of 0.398 and an entrapment efficiency of $66.22 \%$. During cycling and centrifugal testing, the creams (with and without transfersome) did not change color or demonstrate phase separation. Chemical stability analyses of the products were performed using high-performance liquid chromatography.

Results: The remaining glutathione content in the transfersome cream was $83.44 \%$, while that of the non-transfersome cream was $47.92 \%$. In the penetration test using Franz diffusion cells, the transfersome cream demonstrated a cumulative penetration of $4474.44 \mu \mathrm{g} / \mathrm{cm}^{2}$, with a cumulative concentration percentage of $39.60 \%$ and a flux of $510.38 \mu \mathrm{g} / \mathrm{cm}^{-2} \mathrm{~h}^{-1}$. In contrast, the non-transfersome cream demonstrated a cumulative penetration amount of $2793.80 \mu \mathrm{g} / \mathrm{cm}^{2}$, with a cumulative concentration percentage of $24.73 \%$ and a flux of $340.12 \mu \mathrm{g} / \mathrm{cm}^{-2} \mathrm{~h}^{-1}$. In addition, the IC50 value of the transfersome cream preparation was $11.89 \mu \mathrm{g} / \mathrm{mL}$, while that of the non-transfersome preparation was $15.57 \mu \mathrm{g} / \mathrm{mL}$.

Conclusion: Our findings indicate that the use of transfersome increases the stability and penetration of glutathione in cream preparations.

Keywords: Glutathione, Transfersome, Cream, High-performance liquid chromatography, Optimization, Stability test, Antioxidant activity test, Penetration test.

(C) 2020 The Authors. Published by Innovare Academic Sciences Pvt Ltd. This is an open access article under the CC BY license (http://creativecommons. org/licenses/by/4. 0/) DOI: http://dx.doi.org/10.22159/ijap.2020.v12s1.FF033

\section{INTRODUCTION}

Glutathione is a potent antioxidant and is a thiol tripeptide compound found in every cell of the human body. Glutathione consists of three amino acids, namely, L-glutamine, L-cysteine, and L-glycine connected by gamma peptide bonds between the amine cysteine group (which is attached to the peptide bond by glycine) and the carboxyl group of the glutamate side chain [1]. In the body, two forms of glutathione exist reduced glutathione (GSH) and oxidized glutathione (GSSG) [2].

Glutathione in aqueous solutions is very unstable and easily decomposes, while GSSG is less susceptible to decomposition in aqueous solutions and is suitable for use in liquid form [3]. Glutathione can experience a decrease in quality due to the influence of heat, oxygen, and light, which can cause unpleasant odors such as sulfur odors and decreased preparation content [4]. Glutathione in topical preparations can be used to treat various skin issues, including dry and dull skin, the loss of elasticity, and the appearance of excessive lines and wrinkles [5].

Transfersome was first introduced in 1991 by Gregor Cevc. The term transfersome comes from the Latin transferre, which means to carry the whole, and from the Greek soma, which means the body [6]. Transfersome, in the broadest sense, is a compound or aggregate that very easily adapts and responds to its environment. In general, transfersome has a structure consisting of a hydrophilic part (aqueous layer) as its core surrounded by a hydrophobic part (double lipid layer) that can carry active substances with various solubilities [7].

Transfersome as a carrier in a given formulation has a number of advantages, including the ability to change the shape of the formulation so it can pass through narrow pores, improved penetration, the ability to carry active substances of a large solubility range efficiently (up to $90 \%$ ), the ability to make compounds with a high molecular weight low, and the ability to release compounds slowly and gradually. In this study, we compared the stability, antioxidant activity, and penetration of glutathione creams formulated with and without transfersome, a commonly used carrier system.

\section{MATERIALS AND METHODS}

\section{Ingredients}

The materials used were glutathione standard (Jincheng Pharm, China); Emuldage SEPF (BASF, Germany); Cutina GMS (BASF, Germany); Isopropyl Myristate (BASF, Germany); Lanette O (BASF, Germany); Propylene Glycol (BASF, Germany); Glycerin (Merck, Germany); Cetiol CC (BASF, Germany); Myritol (BASF, Germany); Phosphatidylcholine (Merck, Germany); Tween 80 (Merck, Germany); Sodium Phosphate by Anhydrous (Merck, Germany); Potassium Dihydrogen Phosphate (Merck, Germany); Sodium Metabisulfite (Merck, Germany); Dichloromethane (Merck, Germany); DPPH (Merck, Germany); Diethyl Ether (Merck, Germany); and Aquadest (Brataco).

\section{Tools}

High-performance liquid chromatography (Shimadzu, Japan) with an LC-20AT model equipped with a SPD 10A (200 nm) UV-Vis detector; Column C18 $(250 \mathrm{~cm} \times 4.6 \mathrm{~mm} \times 5 \mu \mathrm{m})$; LC-Solution data processors and CBM 102 integrators; UV-Vis spectrophotometry (Shimadzu UV1601 and Jasco); Microsyringe 10 ul (Hamilton Co.Nevada, America); rotary vacuum evaporator (Hahn Shin, China); centrifugator (Hettich Zentrifugen EBA 200, America); Sonicator (Branson 3200, America); rotary vacuum evaporator (Buchi, Switzerland); Particle Size Analyzer (Malvern Zetasizer, UK); Climatic chamber (Nuve Sanayi Malzemeleri Imalat ve Tic. A.S., Turkey); Oven (Memmert); Refrigerator (GEA, Germany); Cell Diffusion Franz; Analytical balance; Stirer; PH meter; Fume hood; Freezer; Separating funnel; Glass beads; Micropipettes; and glassware commonly used in quantitative analysis. 
Steps

Preparing the solvent phase

Approximately $6.8 \mathrm{~g}$ of potassium dihydrogen phosphate was carefully weighed and then dissolved in $1000 \mathrm{~mL}$ of aquadest. The $\mathrm{pH}$ was then adjusted with dilute phosphoric acid (1:10) to $\mathrm{pH}$ 3.0.

\section{Preparing the glutathione standard master solution}

$10 \mathrm{mg}$ of glutathione standard was carefully weighted, then diluted with a buffered phosphate of $\mathrm{pH} 3.0$ to concentrations of $1000 \mu \mathrm{g} / \mathrm{mL}$, $100 \mu \mathrm{g} / \mathrm{mL}$, and $10 \mu \mathrm{g} / \mathrm{mL}$.

\section{Determination of optimum analysis conditions}

Before high-performance liquid chromatography (HPLC) analysis, the maximum wavelength was determined using UV-Vis spectrophotometry. The standard solution used for examining the maximum wavelength was $10 \mu \mathrm{g} / \mathrm{mL}$. The determination of the optimum analysis conditions was performed through varying the flow rate at $0.6,0.8,1.0$, and $1.2 \mathrm{~mL} / \mathrm{min}$.

\section{System suitability test}

The solution for the system suitability test was a standard glutathione solution at a concentration of $10 \mu \mathrm{g} / \mathrm{mL}$, which was injected into the HPLC 6 times.

\section{Selectivity test}

The solution used for the selectivity test was a placebo or cream base that did not contain glutathione. The cream base used was $25 \mathrm{mg}$, which was sonicated for $15 \mathrm{~min}$. After sonication, the cream was transferred into a centrifugation tube and vortexed for $5 \mathrm{~min}$. After that, it was centrifuged at $4000 \mathrm{rpm}$ for $15 \mathrm{~min}$. The formed supernatant was then taken and filtered with a Whatman nylon filter syringe $(0.45 \mu \mathrm{m})$.

\section{Linearity test}

The solution used for the linearity test was a standard glutathione solution at concentrations of $10 \mu \mathrm{g} / \mathrm{mL}, 20 \mu \mathrm{g} / \mathrm{mL}, 40 \mu \mathrm{g} / \mathrm{mL}, 50 \mu \mathrm{g} / \mathrm{mL}$, $80 \mu \mathrm{g} / \mathrm{mL}$, and $150 \mu \mathrm{g} / \mathrm{mL}$.

\section{Accuracy and precision test}

Accuracy and precision tests were performed with glutathione concentrations of $80 \%, 100 \%$, and $120 \%$. For example, an $80 \%$ glutathione concentration was made by mixing $8 \mathrm{mg}$ of standard glutathione with a cream base of up to $500 \mathrm{mg}$. The $100 \%$ concentration was made by mixing $10 \mathrm{mg}$ of standard glutathione with a cream base of up to $500 \mathrm{mg}$. The $120 \%$ concentration was made by mixing $12 \mathrm{mg}$ of standard glutathione with a cream base of up to $500 \mathrm{mg}$. For each concentration, we weighed the sample to $\pm 25 \mathrm{mg}$ and then placed it into a $10-\mathrm{mL}$ volumetric flask and sonicated it for $15 \mathrm{~min}$, with final placement into a centrifuge tube. Before centrifugation, the solution was vortexed for $5 \mathrm{~min}$ then centrifuged at $4000 \mathrm{rpm}$ for $15 \mathrm{~min}$. The supernatant from each concentration was filtered using $0.45 \mu \mathrm{m}$ nylon syringe filters. The $80 \%$ and $120 \%$ concentrations were injected into the HPLC 3 times, with the $100 \%$ concentration was injected 6 times.

\section{Transfersome formulation and optimization of the sodium phosphate-buffered}

The phosphate-buffered solution at $\mathrm{pH} 7.4$ was made by mixing $50 \mathrm{~mL}$ of $0.2 \mathrm{M}$ potassium dihydrogen phosphate with $39.1 \mathrm{~mL} 0.2 \mathrm{~N}$ sodium hydroxide in a $200-\mathrm{mL}$ volumetric flask, then increasing the volume gradually with aquadest to $200 \mathrm{~mL}$. Previously, $0.2 \mathrm{M}$ potassium dihydrogen phosphate was made by weighing $1.36 \mathrm{~g}$ of potassium dihydrogen phosphate powder, dissolved in distilled water in a $50-\mathrm{mL}$ volumetric flask, and a sufficiently small volume was added to reach the measuring flask limit. To prepare the $0.2 \mathrm{~N}$ sodium hydroxide solution, sodium hydroxide was weighed to $0.4 \mathrm{~g}$, then dissolved in $50 \mathrm{~mL}$ of distilled water. The $\mathrm{pH}$ was checked using a $\mathrm{pH}$ meter. Data in Table 1.

\section{Transfersome preparation}

Transfersome was prepared by dissolving phosphatidylcholine and tween 80 , then dissolving it into dichloromethane as much as $15 \mathrm{~mL}$.
Table 1: Transfersome formulation

\begin{tabular}{llll}
\hline Ingredients & $\begin{array}{l}\text { Formulation } \\
\mathbf{1} \text { (gram) } \\
\mathbf{( 9 0 : 1 0 )}\end{array}$ & $\begin{array}{l}\text { Formulation } \\
\mathbf{2} \text { (gram) } \\
\mathbf{( 8 5 : 1 5 )}\end{array}$ & $\begin{array}{l}\text { Formulation } \\
\mathbf{3} \text { (gram) } \\
\mathbf{( 7 5 : 2 5 )}\end{array}$ \\
\hline Glutathione & 0.6 & 0.6 & 0.6 \\
Phosphatidylcholine & 1.35 & 1.275 & 1.125 \\
Tween 80 & 0.15 & 0.225 & 0.375 \\
Buffer phosphate 7.4 & 12 & 12 & 12 \\
Total & 15 & 15 & 15 \\
\hline
\end{tabular}

After complete dissolution, the solution was placed into a roundbottomed flask and applied with a rotary evaporator at $40^{\circ} \mathrm{C}$ with an initial speed of $50 \mathrm{rpm}$. This speed was increased by $25 \mathrm{rpm}$ every $5 \mathrm{~min}$ to reach $150 \mathrm{rpm}$ to remove any organic solvents for $60 \mathrm{~min}$. The solution was then flowed with nitrogen gas for 2 min and left for $24 \mathrm{~h}$ in a closed state. Glutathione (0.6 gram) was then dissolved with phosphate buffer ( $\mathrm{pH} 7.4$ ) as much as $12 \mathrm{~mL}$; then the solution was hydrated to a thin layer in a round-bottomed flask. The flask was then placed on a rotary evaporator without a vacuum at a temperature of $30^{\circ} \mathrm{C}$ and rotated with an initial speed of $50 \mathrm{rpm}$; this speed was then increased by $25 \mathrm{rpm}$ every $5 \mathrm{~min}$ to reach $150 \mathrm{rpm}$ with the help of glass beads that easily peel off. The resulting suspension was removed from the rotary evaporator and then sonicated for $10 \mathrm{~min}$.

\section{Particle size test}

This test used a particle size analyzer at $4^{\circ} \mathrm{C}$. One drop of the sample from each transfersome formulation was dispersed in $10 \mathrm{~mL}$ aquadest, then placed in a cuvette to the ideal limit specified.

\section{Entrapment efficiency test}

Absorption efficiency was measured by calculating the total and free glutathione concentration. The total glutathione concentration was the concentration of glutathione that was absorbed and free in suspension. To separate the free glutathione, a centrifuge was used at a speed of $13,000 \mathrm{rpm}$ for $2 \mathrm{~h}$ at $4^{\circ} \mathrm{C}$. The supernatant formed then contained the free glutathione and was measured using HPLC at a wavelength of $200 \mathrm{~nm}$. Absorption efficiency (EE) was measured using the following equation:

$$
\mathrm{EE}(\%)=\frac{\text { Total concentration }- \text { Freeconcentration }}{\text { Total concentration }} \times 100 \%
$$

\section{Accelerated stability test}

Accelerated stability testing was performed by inserting a number of cream samples into plastic pots. Then they were stored in a climate chamber at storage conditions of $40 \pm 2^{\circ} \mathrm{C}$, with humidity set at $75 \pm 5 \%$ $\mathrm{RH}$. The creams were sampled at $0,1,2$, and 3 months, followed by HPLC analysis. The samples were weighed as much as $25 \mathrm{mg}$ for stability tests at $0,1,2$, and 3 months, then placed in a $10-\mathrm{mL}$ volumetric flask with solvents added to the limit. The solution was then sonicated for $15 \mathrm{~min}$ and placed into a centrifugation tube. Before centrifuging, the solution was vortexed for $5 \mathrm{~min}$. The centrifuge speed was $4000 \mathrm{rpm}$ for $15 \mathrm{~min}$. The supernatant was taken and filtered using a Whatman nylon filter syringe $(0.45 \mu \mathrm{m})$.

\section{Stability cycling test}

This stability test was performed by storing the cream at $4^{\circ} \mathrm{C}$ for $24 \mathrm{~h}$, then removing it and placing it into an oven at a temperature of $40 \pm 2^{\circ} \mathrm{C}$ for $24 \mathrm{~h}$; the treatment consisted of one cycle. This experiment was repeated for as many as six cycles over 12 days. The physical condition of the cream such as color, smell, and presence or absence of phase separation was then observed.

\section{Centrifugal test}

This stability test was intended to determine whether phase separation occurred in the cream samples. Cream samples were centrifuged for $3750 \mathrm{rpm}$ for $5 \mathrm{~h}$. 
Antioxidant activity test and making the DPPH stock solution Five milligrams DPPH was dissolved in $100 \mathrm{~mL}$ of methanol to obtain a concentration of $50 \mu \mathrm{g} / \mathrm{mL}$. The solution was examined for its maximum wavelength using UV-Vis Spectrophotometry.

\section{Making a blank solution}

A total of $1 \mathrm{~mL}$ of the methanol was added to $3 \mathrm{~mL} \mathrm{DPPH}$, then vortexed for $20 \mathrm{~s}$ and incubated for $30 \mathrm{~min}$. After $30 \mathrm{~min}$, the absorbance was measured with the selected maximum wavelength.

\section{Making sample solutions}

The cream samples (500 mg containing $10 \mathrm{mg}$ glutathione) were dissolved in $20 \mathrm{~mL}$ of methanol and then sonicated for $10 \mathrm{~min}$. After sonification, the solution was centrifuged at $4000 \mathrm{rpm}$ for $10 \mathrm{~min}$. The centrifuged filtrate was then diluted to form concentrations of $3 \mu \mathrm{g} / \mathrm{mL}$, $5 \mu \mathrm{g} / \mathrm{mL}, 8 \mu \mathrm{g} / \mathrm{mL}, 10 \mu \mathrm{g} / \mathrm{mL}, 15 \mu \mathrm{g} / \mathrm{mL}$, and $20 \mu \mathrm{g} / \mathrm{mL}$. As much as, $1 \mathrm{~mL}$ of each sample was added to $3 \mathrm{~mL} \mathrm{DPPH}$, then this solution was vortexed for $20 \mathrm{~s}$ and incubated for $30 \mathrm{~min}$. After $30 \mathrm{~min}$, the absorbance was measured with the selected maximum wavelength.

\section{Determination of the \% inhibition value}

From the absorbance obtained from the blank solution and the sample, we calculated the \% inhibition using the following formula:

$$
\% \text { inhibisi }=\frac{\text { Blankabsorbance }- \text { Sampleabsorbance }}{\text { Blank absorbance }} \times 100 \%
$$

\section{Determination of IC50 values}

After the \% inhibition value was obtained, the data were plotted into a graph with concentration as the $\mathrm{X}$-axis and \% inhibition as the Y-axis. From the graph, we then obtained a linear regression equation in the form of $y=a+b x$, with the value of $x$ representing the $\mathrm{IC}_{50}$ value.

\section{Penetration test}

The penetration test was performed using the Franz Diffusion Cell tool. The test membrane used was the skin of female Sprague Dawley mice,

Table 2: Correlation of wavelength with absorbance value

\begin{tabular}{ll}
\hline Wave (nm) & Absorbance \\
\hline 215 & 0.4055 \\
210 & 0.4678 \\
200 & 0.7441 \\
\hline
\end{tabular}

aged 8-10 weeks, with a weight of \pm 200 g. The mice used in the experiment had received a certificate of ethical review from the Health Research Ethics Committee of the Faculty of Medicine, University of Indonesia, Cipto Mangunkusumo Hospital. Before use, the skin of the mouse was shaved and cleaned of sticking fats. The area of the diffusion membrane was $1.77 \mathrm{~cm}^{2}$, with a compartment volume of $15 \mathrm{~mL}$. The compartment was filled with phosphate buffer at $\mathrm{pH} 7.4$ and stirred constantly with a magnetic stirrer at a speed of $250 \mathrm{rpm}$ at $37 \pm 5^{\circ} \mathrm{C}$. Transfersome and non-transfersome cream was weighed as much as $1 \mathrm{~g}$ and applied to the skin. A total of $1 \mathrm{~mL}$ of sample was taken from the receptor compartment periodically for $8 \mathrm{~h}$ using a syringe and replaced with the same amount of phosphate buffer solution at $\mathrm{pH} 7.4$. The sample was taken in the $10^{\text {th }} \mathrm{min}$ at 30; 60 (1 h); 90; 120 (2 h); 180 (3 h); 240 (4 h); 300 (5 h); 360 (6 h); 420 (7 h); and 480 ( $8 \mathrm{~h}) \mathrm{min}$. The samples obtained were measured for absorption using HPLC at a wavelength of $200 \mathrm{~nm}$.

\section{RESULTS AND DISCUSSION}

\section{Extraction}

The wavelength used for HPLC analysis was $200 \mathrm{~nm}$, because the maximum wavelength can cause maximum absorbance. Based on these data, the selected flow rate was $0.8 \mathrm{~mL} / \mathrm{min}$. Even though the flow rate at $1.0 \mathrm{~mL} / \mathrm{min}$ had a larger peak area, the tailing factor of the flow rate was larger than that at $0.8 \mathrm{~mL} / \mathrm{min}$. In addition, the retention time was similar to that shown on USP 41 NF 36, which is 5 min (Tables 2-3).

The system suitability test was needed because there were possible disturbing factors due to variations in the analysis tools and techniques used. The system suitability test was performed 6 times at a concentration of $10 \mu \mathrm{g} / \mathrm{mL}$ to produce a coefficient of variation. Based on the result of the analysis, the coefficient of variation obtained was $0.34 \%$ for the area, $0.34 \%$ for retention time, $1.18 \%$ for tailing factor, $0.90 \%$ for theoretical plate number $(\mathrm{N})$, and $0.90 \%$ for the column efficiency value (height equivalent to a theoretical plate). The coefficient value of variation obtained meets the requirements, which is $<2 \%$ (Table 4 ).

The linear relationship is shown by the correlation coefficient parameters for the linear regression analysis of $y=a+b x$. From the calibration curve, the linear regression value obtained $y=14050 x+$ 68846. With a correlation coefficient of 0.9992 , the glutathione standard meets the linearity requirements because the correlation coefficient value is close to 1 or $>0.9990$. Based on the results of the glutathione standard linearity test, the detection limit value was $6.79 \mu \mathrm{g} / \mathrm{mL}$, and the quantitation limit value was $22.63 \mu \mathrm{g} / \mathrm{mL}$. The smaller the limit of detection and limit of quantification values are, the more sensitive the analytical method. The data shown in Table 5 and Fig. 1.

Table 3: Correlation of flow rate, peak area, retention time, tailing factor theoretical plate, and HETP

\begin{tabular}{llllll}
\hline Flow rate $(\mathbf{m L} / \mathbf{m i n})$ & Peak area $(\boldsymbol{\mu V} / \mathbf{s})$ & Retention time $(\mathbf{m i n})$ & Tailing factor $(\mathbf{T f})$ & Theoretical plate $($ Plat) & HETP $(\mathbf{c m})$ \\
\hline 0.6 & 214,356 & 6.250 & 1.454 & 4781 & 31.373 \\
0.8 & 177,847 & 5.747 & 1.219 & 4015 & 37.361 \\
1.0 & 128,126 & 3.719 & 1.347 & 3539 \\
1.2 & 107,924 & 3.108 & 1.334 & 3097 & 48.438 \\
\hline
\end{tabular}

HETP: Height equivalent to a theoretical plate

Table 4: Result of the system suitability test

\begin{tabular}{llllll}
\hline Concentration $(\boldsymbol{\mu g} / \mathbf{m L})$ & Peak area $(\boldsymbol{\mu V} / \mathbf{s})$ & Retention factor $(\mathbf{m i n})$ & Tailing factor $(\mathbf{T f})$ & Theoretical plate $($ Plat) & HETP $(\mathbf{c m})$ \\
\hline 10 & 163,377 & 5.701 & 1.255 & 5223 & 28.720 \\
& 162,051 & 5.685 & 1.243 & 5249 & 28.576 \\
& 163,581 & 5.671 & 1.246 & 5259 & 28.525 \\
& 163,084 & 5.661 & 1.242 & 5294 & 28.333 \\
Average & 163,455 & 5.67 & 1.212 & 5361 & 27.977 \\
RSD & 163,144 & 5.646 & 1.236 & 5272 & 28.450 \\
& $163,115.33$ & 5.672 & 1.239 & 5276,33 & 28.430 \\
& 554.1295 & 0.0190 & 0.0146 & 47.7312 & 0.2567 \\
\hline
\end{tabular}

HETP: Height equivalent to a theoretical plate 
The selectivity test aims to assess the ability of a method to measure a given substance specifically with the possibility of other components in the sample matrix. The results of the chromatogram obtained are then compared with those of the standard solution. Based on the results of this analysis, in the chromatogram of the placebo solution, there was no interference in the peak of other compounds around the glutathione retention time (Fig. 2).

Accuracy and precision tests were performed by mixing a number of standard glutathione solutions with the cream bases. This is called the simulation method. Calculation of the accuracy is performed by calculating the recovery value ( $\%$ UPK). The recovery value is calculated by comparing the results of the analysis with the actual results. Based on the results of the study in Table 6 , the \%UPK at a concentration of $40 \mu \mathrm{g} / \mathrm{mL}$ was $101.32 \%$, the concentration of $100 \%$ was $100.93 \%$, and the concentration of $120 \%$ was $99.51 \%$. From these data, the glutathione standard has a precision range between 99.51 and $101.32 \%$, which is in accordance with the requirements of $98-102 \%$. Precision testing showed that the coefficient variation at a concentration of $50 \mu \mathrm{g} / \mathrm{mL}$ was $<2 \%$.

Phosphatidylcholine acts as the main constituent in the manufacture of multiple lipid membranes. The phosphatidylcholine used in this study

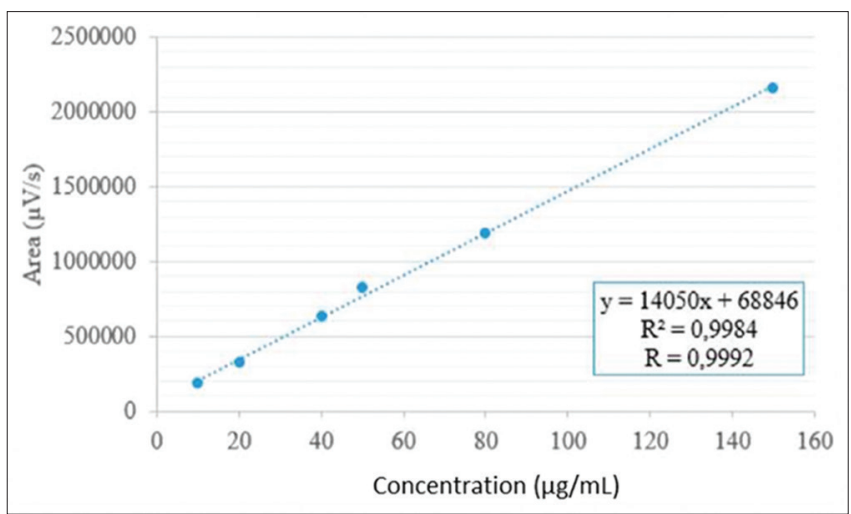

Fig. 1: Calibration curve of the glutathione standard was Phospholipon 90G. Phosphatidylcholine has both hydrophilic and hydrophobic groups; thus it can form a double-layered structure. Phosphatidylcholine was chosen because it is relatively odorless. The surfactant used to make the glutathione transfersome was tween 80 . Tween 80 is used as a surfactant because it also has a hydrophilic and lipophilic structure. Tween 80 has a long hydrocarbon chain that is flexible and not large enough to increase deformability. In addition, Tween 80 can also replace a portion of a double lipid membrane so that it can provide maximum deformability and make the transfersome more elastic. This can make vesicles easier to release the drug. In addition, Tween 80 is a non-ionic surfactant that is less irritant and is better tolerated by the body than other surfactants. Because it is a non-ionic surfactant, Tween 80 penetrates into the intracellular area of the stratum corneum, increasing fluidity and dissolving the lipid component [8-10].

Making transfersome using the layer hydration method consists of a thin-layer formation, with stages of hydration. The thin-layer formation uses a rotary evaporator with the help of a vacuum. Phospholipon and Tween 80 are dissolved first with dichloromethane. The temperature used to make transfersome is $40^{\circ} \mathrm{C}$, at which the methanol as a solvent will evaporate. The use of a vacuum is intended to speed up the evaporation process of the solvents, but the vacuum is only used for a few moments so as not to cause a rapid evaporation process, which may cause uneven thin-layer formation. After the thin layer is formed, the thin layer is flowed with $\mathrm{N}_{2}$ gas for 2 min then stored at $4^{\circ} \mathrm{C}$ for $24 \mathrm{~h}$ to prevent the oxidation of lipids and maximize solvent evaporation [9].

The next stage is the hydration of the thin layer that has been formed. The thin layer is hydrated using a phosphate-buffered at pH 7.4. The vesicle layer will form spontaneously and the hydrating fluid will enter into the dry thin-layer lipids. In the transfersome suspension that has been formed, particle size reduction is done. The reduction in particle size was done using ultrasonication at a $10 \%$ amplitude for $10 \mathrm{~min}$. The time used to reduce the particle size will affect the size of the particles formed. The longer ultrasonication time, the smaller the particle size; however, if the ultrasonication time is too long, it can cause the oxidation and precipitation of phospholipids.

Table 7 shown the Z-average particle size for formulation 1 was $55.65 \mathrm{~nm}$; formulation 2 was $63.56 \mathrm{~nm}$; and formulation 3 was $135.7 \mathrm{~nm}$.

Table 5: Results of the linearity test

\begin{tabular}{|c|c|c|c|c|c|c|}
\hline Concentration $(\mu \mathrm{g} / \mathrm{mL})$ & Peak area $(\mu \mathrm{V} / \mathrm{s})$ & $y i=a+b x$ & $(y-y i)^{2}$ & Residual standard deviation & LOD $(\mu \mathrm{g} / \mathrm{mL})$ & $\mathrm{LOQ}(\mu \mathrm{g} / \mathrm{mL})$ \\
\hline 10 & 188,853 & 209346 & 419963049 & & & \\
\hline 20 & 326,886 & 349846 & 527161600 & & & \\
\hline 40 & 637,274 & 630846 & 41319184 & 31789.48 & 6.79 & 22.63 \\
\hline 50 & 824,840 & 771346 & 2861608036 & & & \\
\hline 80 & $1,189,985$ & 1192846 & 8185321 & & & \\
\hline \multirow[t]{2}{*}{150} & $2,162,780$ & 2176346 & 184036356 & & & \\
\hline & & Total & 4042273546 & & & \\
\hline
\end{tabular}

LOD: Limit of detection, LOQ: Limit of quantification

Table 6: Results of the accuracy and precision test

\begin{tabular}{|c|c|c|c|c|c|c|}
\hline Concentration $(\mu \mathrm{g} / \mathrm{mL})$ & Peak area $(\mu \mathrm{V} / \mathrm{s})$ & Measured concentration $(\mu \mathrm{g} / \mathrm{mL})$ & Recovery (\%) & Average (\%) & RSD & KV (\%) \\
\hline & 637,364 & 40.46 & 101.16 & & & \\
\hline \multirow[t]{4}{*}{$40(80 \%)$} & 636,981 & 40.44 & 101.09 & 101.32 & 0.3421 & 0.34 \\
\hline & 640,486 & 40.69 & 101.72 & & & \\
\hline & 779,984 & 50.61 & 101.23 & & & \\
\hline & 777,230 & 50.42 & 100.84 & & & \\
\hline \multirow[t]{5}{*}{$50(100 \%)$} & & & & 100.93 & 0.5503 & 0.55 \\
\hline & 777,415 & 50.43 & 100.86 & & & \\
\hline & 776,369 & 50.36 & 100.72 & & & \\
\hline & 772,387 & 50.07 & 100.15 & & & \\
\hline & 907,501 & 59.69 & 99.48 & & & \\
\hline \multirow[t]{2}{*}{$60(120 \%)$} & 907,031 & 59.66 & 99.43 & 99.51 & 0.1006 & 0.01 \\
\hline & 908,677 & 59.77 & 99.62 & & & \\
\hline
\end{tabular}




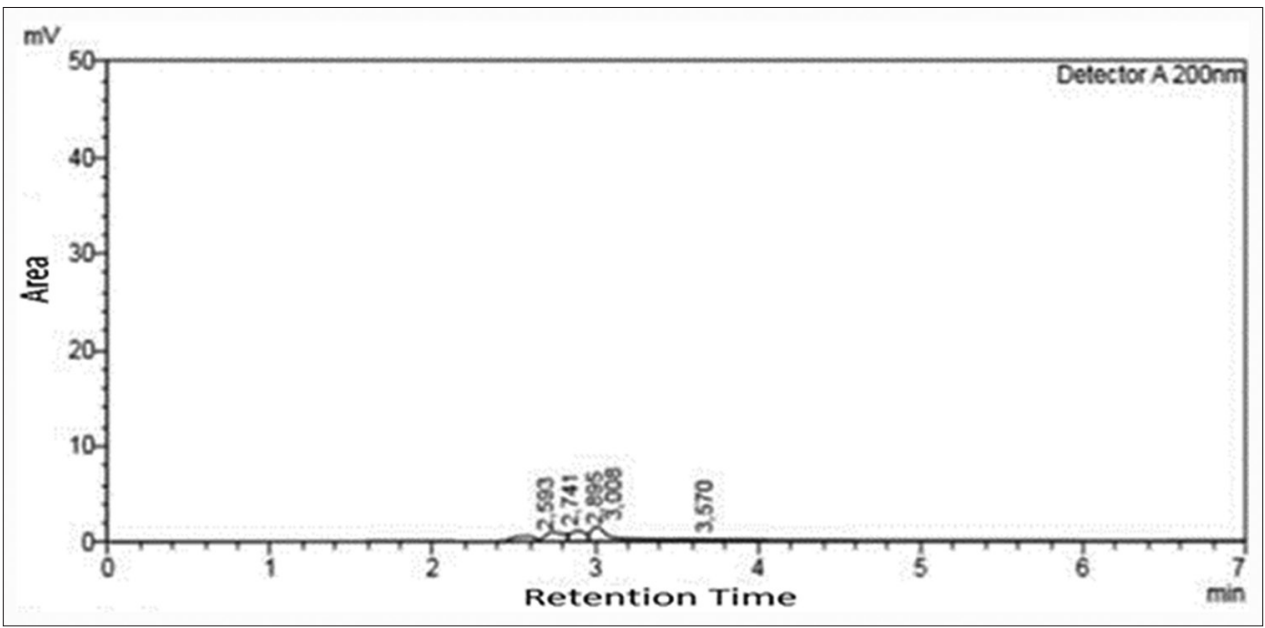

Fig. 2: Results of the selectivity test

Table 7: Results of transfersome optimization

\begin{tabular}{llll}
\hline Formula & Z-average (nm) & PDI (nm) & Efficiency entrapment (\%) \\
\hline F1 & 55.65 & 0.398 & 66.22 \\
F2 & 63.56 & 0.406 & 64.39 \\
F3 & 135.7 & 0.417 & 61.14 \\
\hline
\end{tabular}

PDI: Polydispersity index

The Z-average value was used to determine the particle size because the Z-average is the main and most stable parameter produced by the DLS method. Based on these data, F1 had the smallest particle size. This shows that the greater the concentration of phosphatidylcholine, the smaller the particle size obtained, and the greater the amount of surfactant, the greater the particle size obtained (Fig. 3).

The polydispersity index (PDI) value that can be obtained by the DLS method is in the range $0-0.6$. If the PDI value obtained is small or close to 0 , the spread of the particle size is evenly distributed or homogeneous. Whereas, if the IPD value obtained $>0.6$, samples have an increasingly broad distribution value [11]. PDI values can increase with increasing particle size because large particles tend to aggregate. From the results of the adsorption efficiency test, the greater the amount of phospholipids used, the greater the absorption efficiency. If the amount of phospholipids increases, the formation of the vesicles will also increase so that the absorption efficiency will be more optimal. In addition to the decreasing surfactant concentration, the absorption efficiency is even greater.

The purpose of this cycling test was to accelerate the changes in storage conditions that usually occur under normal conditions so that the preparation will experience varying levels of stress. The physical appearance of each glutathione preparation was observed before and after the test. The physical transfersome glutathione cream did not change color and still smelled of phosphatidylcholine. Whereas the non-transfersome cream did not change color, but there was a slight smell of sulfur in the cream preparation. However, from the two creams, no phase separation was observed and they remained homogeneous. Thus, it can be concluded that both creams are physically stable; however, glutathione transfersome creams appear to be more stable than non-transfersome creams.

This centrifugation test was likened to the gravitational force that will be received by a number of creams for 1 year of storage. Based on the results of the experiment, the transfersome glutathione cream and nontransfersome cream after centrifugation did not show any separation of the water phase and oil phase. The creams were likely protected from phase separation because of the use of emulsifying agents, which served to maintain the cream preparation. In addition, the homogenization

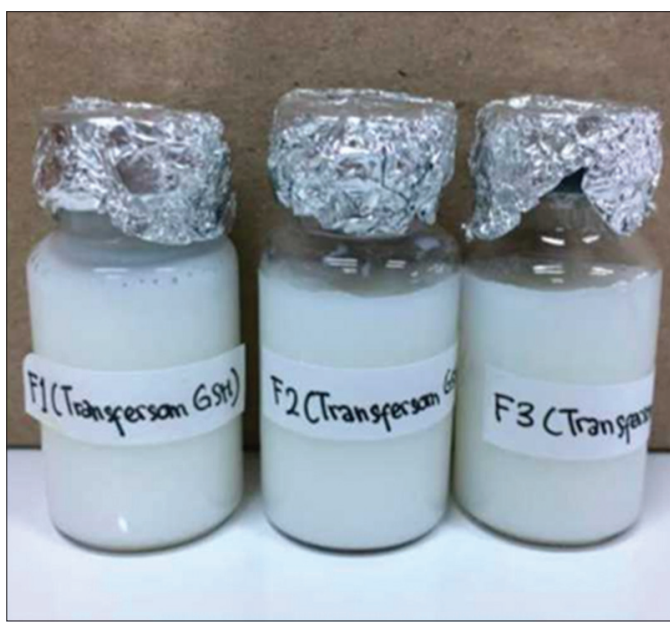

Fig. 3: Transfersome suspensions

process can also prevent separation. Our results indicated that both creams can withstand the force of gravity for 1 year.

In cosmetic preparations, the accelerated stability test can be performed in 30 days or 90 days, but for chemical stability and determining shelf life, it is recommended to carry out testing for a minimum of 3 months with the same conditions as in pharmaceutical products [12] (Gianeti et al. 2012). The accelerated stability test was performed within 3 months as previously performed by Padamwar 2006 and Gianeti 2012 .

The amount of glutathione remaining from each cream decreased with increasing testing time. This is because glutathione is easily oxidized, with the thiol group easily oxidized to a disulfide group, which causes the glutathione to lose its antioxidant activity [13]. In addition, it can be caused by glutathione instability in oil cream formulations exposed to water and at high storage temperatures. Glutathione in the $\mathrm{pH}$ range of 5.0-8.0 can lose $10-15 \%$ of its level at room temperature storage, while storage at temperatures below $15^{\circ} \mathrm{C}$, the glutathione lost is about $0-5 \%$ [14]. Reduced glutathione levels can also result because glutathione can be oxidized by oxygen molecules and the presence of metals (such as iron) in the preparation. From this accelerated stability test, we were able to determine the value of the shelf life for both creams using a zero-order reaction. The shelf life for the transfersome cream was determined to be 3.5 months, while that for the non-transfersome cream was 1.1 months. Result shown in Table 8 and Fig. 4.

Although the glutathione in this study was formulated in the form of transfersome, the storage period appears to be reduced. This is 
probably due to the leakage process that occurs in the transfersome vesicles, thereby reducing the entrapment efficiency of glutathione. Transfersome vesicles containing lipids can degrade with increasing

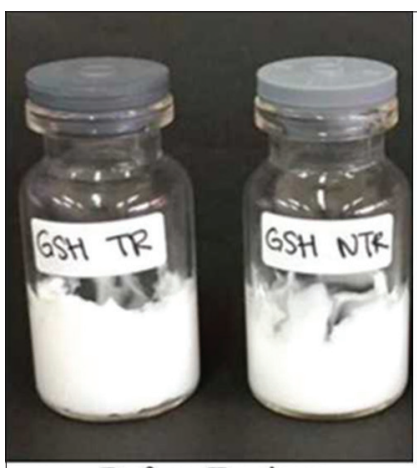

Before Testing

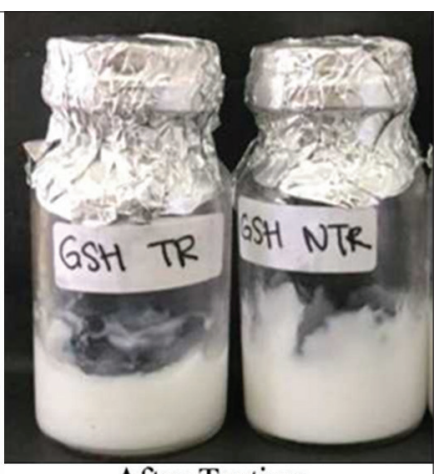

After Testing
Fig. 4: Results of the cycling test

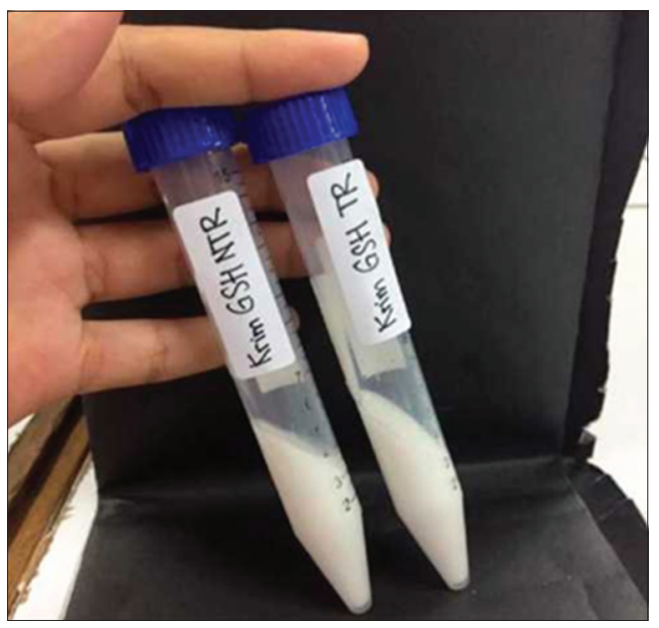

Fig. 5: Results of the centrifuge test temperature. In addition, chemical degradation processes such as hydrolysis and oxidation occur in double lipid layers and can cause the formation of short-chain lipids that can form membrane-soluble lipid compounds that affect the stability of the transfersome vesicles [15].

After measuring the absorbance values, we determined the \% inhibition value and obtained the linear regression equation, which was $y=2.8294 \mathrm{x}+16.349$ for the transfersome cream and $\mathrm{y}=2.5925 \mathrm{x}$ + 96432 for the non-transfersome cream. From the linear regression equation, the $\mathrm{IC}_{50}$ value for the transfersome cream was determined to be $11.89 \mu \mathrm{g} / \mathrm{mL}$, while that for the non-transfersome cream was $15.57 \mu \mathrm{g} / \mathrm{mL}$. Based on these results, we determined the antioxidant status of each cream based on the criteria of Phongpaichit 2007. Indeed, if the $\mathrm{IC}_{50}>250 \mu \mathrm{g} / \mathrm{mL}$ the antioxidants are not active; $\mathrm{IC}_{50}$ $>100-150 \mu \mathrm{g} / \mathrm{mL}$ are weak antioxidants; $\mathrm{IC}_{50}>50100 \mu \mathrm{g} / \mathrm{mL}$ are moderate antioxidants; $\mathrm{IC}_{50} 10-50 \mu \mathrm{g} / \mathrm{mL}$ are strong antioxidants; and $\mathrm{IC}_{50}<10 \mu \mathrm{g} / \mathrm{mL}$ are very strong antioxidants. Result shown in Tables 9-10 and Fig. 5-6.

Table 8: Results of the accelerated stability test

\begin{tabular}{lllll}
\hline \multirow{2}{l}{ Transfersome cream } & & \multicolumn{2}{l}{ Non-transfersome cream } \\
\cline { 1 - 1 } \cline { 5 - 5 } Month & Recovery (\%) & & Month & Recovery (\%) \\
\hline 0 & 99.92 & & 0 & 99.84 \\
1 & 96.97 & & 1 & 77.78 \\
2 & 89.78 & & 3 & 59.90 \\
3 & 83.44 & & & 47.92 \\
\hline
\end{tabular}

Table 9: Results of the antioxidant activity test

\begin{tabular}{lll}
\hline Type of cream & $\begin{array}{l}\text { Linear regression } \\
\text { and coefficient }\end{array}$ & IC50 $(\mu \mathrm{g} / \mathrm{mL})$ \\
\hline \multirow{2}{*}{ Transfersome Cream } & $\mathrm{y}=2.8294 \mathrm{x}+16,349$ & \\
& $\mathrm{r}=0.9787$ & 11.89 \\
Non-Transfersome Cream & $\mathrm{y}=2.5925 \mathrm{x}+9,6432$ & \\
& $\mathrm{r}=0.9611$ & 15.57 \\
\hline
\end{tabular}

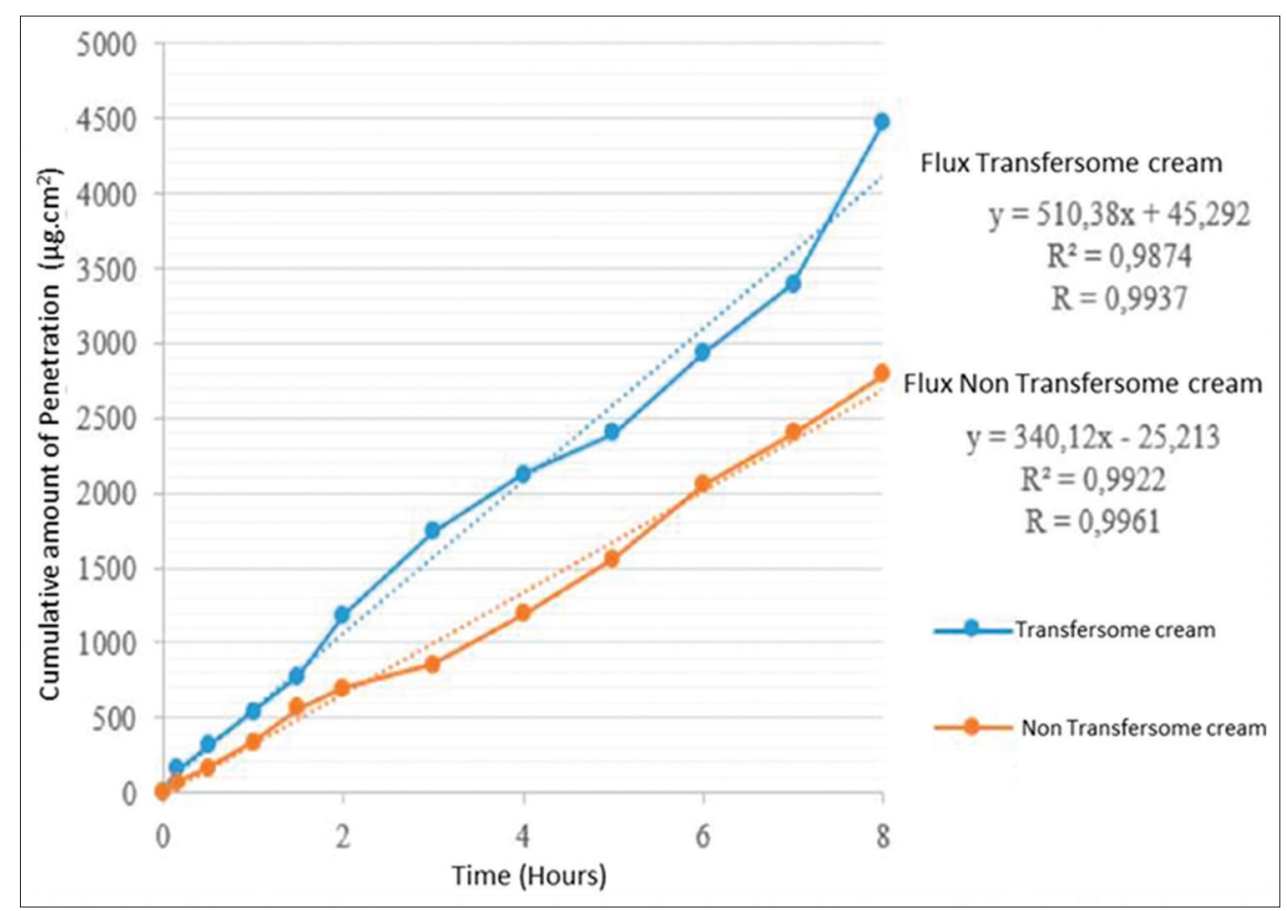

Fig. 6: Transfersome and non-transfersome cream 
Table 10: Results of the penetration test using Franz cell diffusion

\begin{tabular}{lll}
\hline & $\begin{array}{l}\text { Transfersome } \\
\text { cream }\end{array}$ & $\begin{array}{l}\text { Non-transfersome } \\
\text { cream }\end{array}$ \\
\hline $\begin{array}{l}\text { Total penetration cumulative } \\
\left(\mu \mathrm{g} / \mathrm{cm}^{2}\right)\end{array}$ & 4474.44 & 2793.79 \\
$\begin{array}{l}\text { Total penetration cumulative } \\
(\%)\end{array}$ & 39.60 & 24.73 \\
Fluks $\left(\mu \mathrm{g} / \mathrm{cm}^{-2} \mathrm{~h}^{-1}\right)$ & 510.38 & 340.12 \\
\hline
\end{tabular}

The in vitro penetration test had two main parameters, namely, the cumulative amount of the penetrated substance $\left(\mu \mathrm{g} / \mathrm{cm}^{2}\right)$ and the penetration rate (flux) [9]. Flux values are obtained from the slope of the line or the slope of the linear curve in steady-state and are obtained from a comparison between the cumulative amounts of penetration to time. Based on the data, it can be seen that the cumulative concentrated amount in the transfersome preparations is greater than that of the nontransfersome preparations. It can also be seen that the transfersome preparations have higher flux than the non-transfersome preparations. The cumulative amount of penetration can be influenced by factors such as the composition of the vesicles, vesicle size, membrane fluidity, elasticity, absorption efficiency, and method of manufacture [15].

The transfersome preparation contains phospholipids with a high affinity for biological membranes so that the phospholipid vesicles can join the intracellular lipid layer, which results in increased transfersome permeability. This can result in a greater transfer of the cream permeation compared with non-transfersome creams [9]. In addition, transfersome contains a surfactant that is an edge activator that functions to destabilize vesicles and increase deformability so that it allows increased glutathione penetration. Vesicles act as carriers of substances, where intact vesicles penetrate the stratum corneum under the influence of the transcutaneous hydration gradient. With the ability of vesicles to penetrate the stratum corneum spontaneously, the permeation ability of the transfersome is increased. Phospholipid vesicles serve to penetrate the stratum corneum and then modify the lipids between cells so as to increase overall fluidity, which causes an increased amount of glutathione to penetrate the skin.

\section{CONCLUSION}

The optimum analytical conditions for analyzing glutathione in antiaging cream preparations involved using an HPLC system with a C18 column and a UV-Vis detector, with an optimum wavelength of $200 \mathrm{~nm}$ and a flow rate of $0.8 \mathrm{~mL} / \mathrm{min}$. These conditions are in accordance with the requirements proposed, where linearity, selectivity, and accuracy and precision testing met the required criteria. Glutathione formulated as transfersome has a ratio of phosphatidylcholine to tween 80 of 90:10. This is because in comparison, these transfersome preparations have a small particle size and PDI, with a high absorption efficiency.

The results of the accelerated stability test showed that the amount of glutathione remaining in the cream transfersome preparations was $83.44 \%$, while that of the non-transfersome cream was $47.92 \%$. The results of the cycling test and the centrifugal test showed that the transfersome and non-transfersome preparations had no color change or phase separation and were resistant to gravity for 1 year of storage. However, for the non-transfersome cream, during the cycling test, a small amount of sulfur odor was detected from the preparation. In the transfersome and non-transfersome creams, the glutathione preparations were determined to have high antioxidant activity. In addition, penetration test results showed that the transfersome cream was able to increase the cumulative amount and flux of the penetrated glutathione better than the non-transfersome cream.

After this study, the cream preparations were stored at temperatures below $15^{\circ} \mathrm{C}$ so that the physical and chemical stability of the cream and the compounds contained could be maintained during the storage period, given the volatile nature of the glutathione compound. In addition, future studies are necessary to analyze other compounds that may be present in the formulations, including by-products of oxidized glutathione.

\section{CONFLICTS OF INTEREST}

All authors have none to declare.

\section{REFERENCES}

1. Morris G, Anderson G, Dean O, Berk M, Galecki P, Martin-Subero M, et al. The glutathione system: A new drug target in neuroimmune disorders. Mol Neurobiol 2014;50:1059-84.

2. Weschawalit S, Thongthip S, Phutrakool P, Asawanonda P. Glutathione and its antiaging and antimelanogenic effects. Clin Cosmet Investig Dermatol 2017; 10:147-53.

3. Watanabe F, Hashizume E, Chan GP, Kamimura A. Skin-whitening and skin-condition-improving effects of topical oxidized glutathione: A double-blind and placebo-controlled clinical trial in healthy women. Clin Cosmet Investig Dermatol 2014;7:267-74.

4. Sakai Y, Kayahashi S. Method for Improving Storage Stability of Glutathione. Patent Application; 2010.

5. Hireche A, Kherouatou NC, Ribouh A, Abadi N, Shi MJ, Satta D. Polymorphic deletions of glutathione S-transferases M1, T1 and bladder cancer risk in Algerian population. Asian J Pharm Clin Res 2018;11:458-62.

6. Bharadia PD, Modi CD. Transfersomes: New dominants for transdermal drug delivery. Am J Pharm Tech Res 2012;2:2249-3387.

7. Salager JL. Surfactants types and uses. Los Andes: Laboratory of formulation, interfaces rheology and processes. J Am Oil Chem Soc 2002;65:1000-6.

8. El Zaafarany GM, Awad GA, Holayel SM, Mortada ND. Role of edge activators and surface charge in developing ultradeformable vesicles with enhanced skin delivery. Int J Pharm 2010;397:164-72.

9. Zafaruddin M, Kuchana V. Design and characterization of transfersomal gel of repaglinide. Int Res J Pharm 2015;6:38-42.

10. Vinod KR, Kumar MS, Anbazhagan S, Sandhya S, Saikumar P, Rohit RT, et al. Critical issues related to transfersomes-novel vesicular system. Acta Sci Pol Technol Aliment 2012;11:67-82.

11. Koo SH, Lee JS, Kim GH, Lee HG. Preparation, characteristics, and stability of glutathione-loaded nanoparticles. J Agric Food Chem 2011;59:11264-9.

12. Harbin R, Stephens L. Extended Storage of Reduced Glutathione Solution. Patent Application US; 2004.

13. Khan AR, Taneja P. Cationic peptide lactoferricin b inhibits glutathione S-transferase P1 from human placenta and breast cancer cell line Mda$\mathrm{Mb}-231$ preventing anticancer drug metabolism. Int J Pharm Pharm Sci 2015;8:238-41.

14. El Maghraby GM, Barry BW, Williams AC. Liposomes and skin: From drug delivery to model membranes. Eur J Pharm Sci 2008;34:203-22.

15. Padamwar MN, Pokharkar VB. Development of vitamin loaded topical liposomal formulation using factorial design approach: Drug deposition and stability. Int J Pharm 2006;320:37-44. 